http://dx.doi.org/10.30681/23588403v13i0206

\title{
O GUARANI: UMA CONSTRUÇÃO ALENCARIANA DO IDEAL NACIONAL
}

Data de recebimento: $26 / 10 / 2019$

Aceite: $25 / 01 / 2020$

Caio Derllan Ribeiro FIGUEIREDO (UEFS)

Marcos BOTELHO (UEFS)

Resumo: Esse artigo busca discutir a construção da identidade nacional na obra $O$ Guarani (1857), de José de Alencar, partindo de uma perspectiva analítica sobre o início da criação da nacionalidade trazida pelo Romantismo no século XIX e o conceito de identidade discutido por Stuart Hall, além do desenvolvimento do mito nacional abordado por Renato Ortiz.

Palavras-chave: Identidade. Mito. Nação. Alencar.

Abstract: This article seeks to discuss the construction of national identity in the work $\mathrm{O}$ Guarani (1857), by José de Alencar, starting from an analytical perspective on the beginning of the creation of nationality brought by Romanticism in the 19th century and the concept of identity discussed by Stuart Hall, in addition to the development of the national myth addressed by Renato Ortiz.

Keywords: Identity. Myth. Nation. Alencar.

\section{Introdução}

O Guarani de José de Alencar é um romance indianista que apresenta personagens idealizados, que seguem uma divisão maniqueísta da moral. Existe uma construção épica na história, em que os personagens passam por diversas aventuras, iniciando uma jornada em torno de um objetivo, e em volta dessas aventuras, a liricidade entra, embalado pelas paixões que envolvem a trama.

Após a independência brasileira conquistada em 1822, começa a permear a ideia de constituição de uma identidade nacional para o Brasil. Nesse processo, o Romantismo se estabelece como referência estética para construção artística da nacionalidade, e é nesse cenário que José de Alencar destaca-se com sua vasta produção romancista.

Em meio a conquista da independência do Brasil, foi necessário criar e consolidar uma cultura artística que justificasse o orgulho de nação independente e que representasse a existência do país no mundo. Dessa forma, a classe artística e elitista começa a se aproximar do 
ideal trazido pela Revolução Industrial e a Revolução Francesa, a luta pela classe, que nesse caso seria a luta pela própria nação.

\section{DESENVOLVIMENTO}

Em seu livro "A identidade cultural na pós-modernidade" Hall afirma que "a identidade é um assunto amplamente discutido na teoria social” (2000, p.03). Assim, o autor propõe que as questões de identidade devem ser discutidas a fim de compreender as relações do indivíduo no ambiente social. Partindo dessa premissa, Hall explica como as identidades existem numa percepção mais ampla, que ao invés de se unificar, se fragmenta, tornando-se portanto mutáveis. Para o autor: "As velhas identidades que por tanto tempo estabilizaram o mundo social estão em declínio, fazendo surgir novas identidades e fragmentando o indivíduo moderno, até aqui visto como um sujeito unificado" (HALL, 2000. p.07).

A formação da identidade se torna fragmentada, pois o sujeito parte de um deslocamento de ideais nacionais, religiosos, midiáticos, artísticos, políticos etc. O que existe é um mosaico de "opções" de identificação que podem ou não classificar o indivíduo. Por conta do desejo de criar a identidade da nação, a literatura brasileira começa a empregar a figura do índio no ideário romântico nacional como forma de moldá-lo como herói, representante nacional, como ocorria nas representações dos cavaleiros medievais.

Para tanto, vale ressaltar que a busca pela identidade se dá também em detrimento do reconhecimento do negro na constituição do Brasil, sendo mais vantajoso colocar o índio como herói, do que um negro escravizado como símbolo nacional. José de Alencar com sua vasta obra, tem o objetivo de produzir uma literatura unicamente brasileira, sem o contato com a Europa, retratando a realidade do Brasil, mostrando principalmente o mundo selvagem (conferida aos índios) e a relação com os brancos.

Alencar segue com sua obra para compor uma identidade nacional, ainda que idealizada, formada pela ausência do pais na representação de um ícone da nação. Iniciando a jornada de implementar o índio como símbolo do Brasil, o objetivo de Alencar em O Guarani, é estabelecer a figura do índio como indicador de uma raça puramente brasileira. É percebido no livro a preocupação do autor em promover uma obra com personagens que se aproximem da realidade, dando enfoque a construção dos ambientes, a escolha das palavras (apresentando algumas de origem indígena), fazendo com que o leitor se sinta em uma aventura unicamente brasileira. 


\section{Revista de Estudos Acadêmicos de Letras}

A narrativa se constrói entre dois grupos distintos: os índios e os brancos portugueses. O protagonista da história é o índio Peri, que é um protegido do D. Antônio de Mariz, dono de um casarão às margens do Rio Paquequer. O romance inicia com a descrição de cada detalhe do ambiente onde irá se passar a história, descreve de forma contemplativa o rio Paquequer, as serras e florestas que o cercam, até chegar ao casarão, representado como uma fortaleza, dando semelhança a um castelo medieval.

Peri é mostrado como um típico bom selvagem, dotado das mais nobres morais, de força e coragem como nenhum outro homem, além da mais pura devoção a Ceci. O primeiro contato do índio com o homem branco se dá quando Peri salva Ceci e a torna sua figura de adoração. É perceptível ao longo da história como Alencar encara a cultura indígena como aspecto importante da nacionalidade. Existe uma relação mútua de heroísmo e nobreza dividida entre o índio, Peri, e os brancos portugueses, Álvaro e D. Antônio de Mariz. O que leva a questão propriamente trabalhada pelo autor, que é o orgulho da pátria cruzada a partir da miscigenação.

Além de trazer um modelo de raça brasileira pela figura do índio, Alencar estabelece uma dualidade. Esse conceito dual se dá pelo trato da sexualidade e aparência trazida em Ceci e Isabel. Cecilia seria demonstrada como uma mulher angelical, de pele alva, simbolizando toda a pureza e dotes femininos, e Isabel, de pele escura, retratada como símbolo do pecado, sensualidade e prazer.

Ao construir o herói em $O$ Guarani, Alencar cria uma simbologia para o ideal da nacionalidade, trazendo pra figura do índio o patamar de representante da supremacia brasileira e do sentimento ufanista. Renato Ortiz, em sua obra "Cultura brasileira e identidade nacional" (2006), defende a ideia de identidade como um discurso conduzido pelo intelectual, sendo um mediador simbólico pra formulação de modelos de identidade e agente das construções de interpretações sobre a realidade no processo de autoafirmação. Desse modo, a narrativa de nação se dá por meio “de uma série de histórias, imagens, panoramas, cenários, eventos históricos, símbolos e rituais nacionais que simbolizam ou representam as experiências partilhadas, as perdas, os triunfos e os desastres que dão sentido à nação". (Hall, 2006, p. 52).

O desenvolvimento dessa história épica em conjunto à lírica do amor, constrói o imaginário da nação, da relação de conformidade do branco colonizador e do índio colonizado. A nacionalidade apresentada na narrativa alencariana cria uma dimensão, imersa na idealização, com descrições exuberantes marcando a importância da relação com a terra, com a natureza tropical, acompanhado pelo tom exótico, diálogos dramáticos, a retomada de memórias, que ajudam compor os recursos estéticos para construção da imagem nacional. Ao mesmo tempo que esses elementos ajudam a resgatar o mito fundador, abrem espaço para um novo olhar sobre 
uma nova construção identitária ao revelar os primeiros sinais de independência, partindo de uma formação artística necessariamente brasileira. Essa afirmação pode ser percebida na cena final do livro, que retrata de forma alegórica o início de um novo Brasil. Peri e Ceci seriam os formadores da nova civilização, o Adão e Eva brasileiros.

\section{Conclusão}

Através do romance $O$ Guarani, José de Alencar se destacou na tentativa de reivindicar e reinventar o homem brasileiro pela literatura. Na construção de um símbolo nacional, o índio acaba sendo posto como protagonista sob um viés de representação de uma raça primitiva, pura e casta. Sua caracterização é feita assemelhando-se a de um herói, dotado dos mais exuberantes dotes e da mais nobre moral. Esses aspectos configuram necessariamente no mito do "Bom Selvagem", trazido por Rousseau, que estabelece que o homem primitivo é integro e bom, e que na verdade o meio é que o corrompe.

A necessidade de autoafirmação da literatura brasileira fez com que se trouxesse o índio para satisfazer esse papel de símbolo da nação. O que houve apenas foi condicioná-lo aos parâmetros corretos de aceitação. Peri é um modelo de indivíduo perfeito, dotado de beleza, força, coragem, lealdade. Como protagonista, ele carrega as características necessárias para o molde de cavaleirismo medieval brasileiro, sendo assim um homem mais civilizado do que um sujeito ocultado pela barreira da floresta tropical.

Peri representa ideias, formas e forças que marcam a criação de uma nova identidade ao Brasil e rompe com a cultura europeia. Alencar buscava mostrar por meio das aventuras do índio, que o Brasil também possuía um herói nacional e que a tradição cultural brasileira estava à altura da europeia. O que torna ainda mais atrativo na história de José de Alencar, é o tratamento mítico que Peri recebe, sendo posto de forma alegórica como precursor do início da nação.

Alencar conseguiu traçar um perfil para sociedade brasileira, visto que seu objetivo era desenvolver uma literatura unicamente nacional. O índio torna-se o super-homem que encarna bem as qualidades que o autor lhe confere como protetor da terra e da pátria. Peri condiciona a imagem idealizada de um novo pais, uma imagem que permanece como mito histórico de fundação, dando concretude na vontade de ser brasileiro e no desejo de pertencer a essa nova terra. 


\section{Referências}

ORTIZ, Renato. O Guarani: um mito de fundação da brasilidade. In: Ciência e cultura, no 40, março 1988.

ALENCAR, José de. O Guarani. São Paulo: Editora Martin Claret, 1999.

HALL, S. A identidade cultural na pós-modernidade. 6. ed. Rio de Janeiro: DP\&A.

Editora, 2001.

ROUSSEAU, Jean-Jacques. Discurso sobre a origem e os fundamentos da desigualdade entre os homens. Trad. Maria Ermantina Galvão. 3 ed., São Paulo: Martins Fontes, 2005. 